\title{
Communications
}

Lanthanide Silicates

DOI: $10.1002 /$ anie.200602849

\section{Optical Detection of Solid-State Chiral Structures with Unpolarized Light and in the Absence of External} Fields**

Duarte Ananias, Filipe A. Almeida Paz, Luís D. Carlos, Carlos F. G. C. Geraldes, and João Rocha*

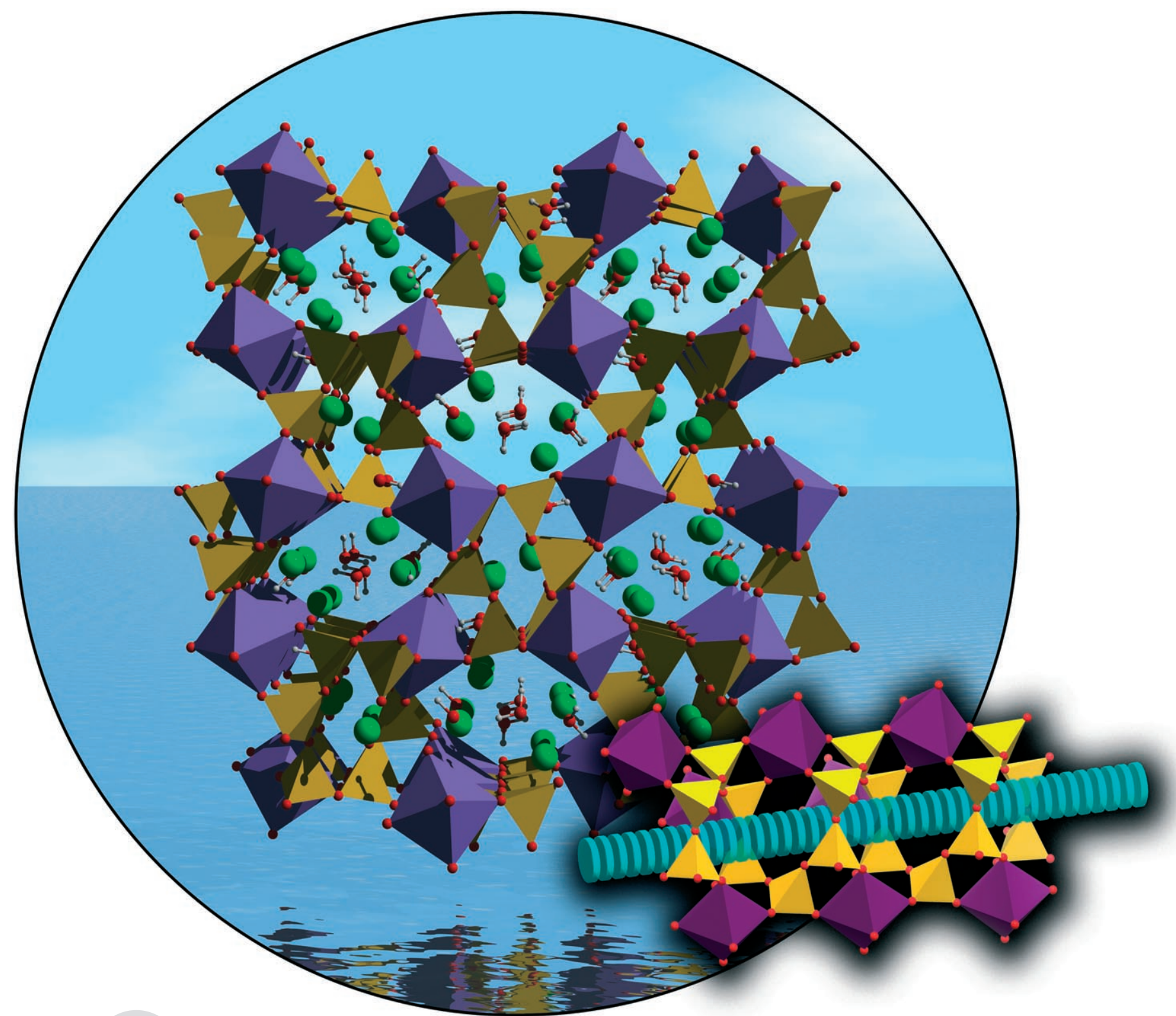

Angewandte

Chemie 
Z eolites are microporous aluminosilicate materials of considerable industrial importance because they are excellent molecular sieves, ion exchangers, and heterogeneous catalysts. With the advent of the nanotechnology era, and increasing interest in the use of molecular sieves for device applications, novel zeolite-type materials containing stoichiometric amounts of lanthanide (Ln) metals that exhibit photoluminescence and magnetic properties have been investigated. ${ }^{[1-3]}$ Herein we report the remarkable framework of $\mathrm{Na}_{3}\left[(\mathrm{Y}, \mathrm{Ln}) \mathrm{Si}_{3} \mathrm{O}_{9}\right] \cdot 3 \mathrm{H}_{2} \mathrm{O}(\mathrm{Ln}=\mathrm{Eu}, \mathrm{Tb}, \mathrm{Er}, \mathrm{Ce})$, an unprecedented chiral, photoluminescent, and microporous Lnsilicate system. Only two zeolite-type silicates exhibit chiral polymorphism, namely zeolite beta and ETS-10, but neither of these materials is photoluminescent. ${ }^{[4,5]}$ The crystal structure of $\mathrm{Na}_{3}\left[(\mathrm{Y}, \mathrm{Ln}) \mathrm{Si}_{3} \mathrm{O}_{9}\right] \cdot 3 \mathrm{H}_{2} \mathrm{O}$ materials displays $\left(\mathrm{Si}_{3} \mathrm{O}_{9}\right)_{\infty}$ chiral spirals interconnected by $\left\{(\mathrm{Y}, \mathrm{Ln}) \mathrm{O}_{6}\right\}$ octahedra, and it exhibits a statistical excess of one enantiomer over the other. For the first time, we show that $\mathrm{Eu}^{3+}$ photoluminescence spectroscopy with excitation by unpolarized light in the absence of an external magnetic field is able to identify, and possibly quantify, enantiomeric domains in chiral frameworks. This enantioselectivity phenomenon may be of importance in the context of fundamental interactions between light and condensed matter.

Although conventional zeolites are built up of tetrahedral $\left\{\mathrm{SiO}_{4}\right\}$ and $\left\{\mathrm{AlO}_{4}\right\}$ units, microporous silicates whose frameworks contain transition-metal heteropolyhedra have been known since the early 1990s. ${ }^{[1-3]}$ The most prominent member of this family is titanosilicate ETS-10, which contains $\left\{\mathrm{TiO}_{6}\right\}$ and $\left\{\mathrm{SiO}_{4}\right\}$ units. ${ }^{[5]}$ The constituent elements of heteropolyhedral silicates have been recently extended to lanthanides, and thus properties such as photoluminescence and magnetism have been explored. However, so far only a handful of microporous (stoichiometric) lanthanide silicates are known. ${ }^{[2]}$

Previously, chirality involving lanthanide complexes has been sensed by magnetochiral dichroism $(\mathrm{MChD})^{[6,7]}$ and

[*] Dr. D. Ananias, Dr. F. A. Almeida Paz, Prof. J. Rocha

Departamento de Química

CICECO

Universidade de Aveiro

3810-193 Aveiro (Portugal)

Fax: (+351) 234-370-730

E-mail: rocha@dq.ua.pt

Prof. L. D. Carlos

Departamento de Física

CICECO

Universidade de Aveiro

3810-193 Aveiro (Portugal)

Dr. D. Ananias, Prof. C. F. G. C. Geraldes

Departamento de Bioquímica

Universidade de Coimbra

3001-401 Coimbra (Portugal)

[**] We thank the Portuguese Foundation for Science and Technology (FCT), POCTI, and FEDER, FAME NoE for financial support of this work.

(2) Supporting information for this article is available on the WWW under http://www.angewandte.org or from the author. circular dichroism (CD) methods, such as Ln-centered absorption, ligand absorption, and Ln-centered circularly polarized luminescence (CPL). ${ }^{[8,9]}$ Whereas CPL measures the difference in emission intensity between left and right circularly polarized light, $\mathrm{MChD}$ evaluates the difference in luminescence intensity in the directions parallel and antiparallel to an externally applied magnetic field using unpolarized light (e.g., from a $\mathrm{Hg}$-discharge lamp). Enantiodiscrimination typically uses the magnetic dipole-allowed $\mathrm{Eu}\left({ }^{5} \mathrm{D}_{0} \rightarrow{ }^{7} \mathrm{~F}_{1}\right)$, $\mathrm{Tb}\left({ }^{5} \mathrm{D}_{4} \rightarrow{ }^{7} \mathrm{~F}_{5}\right)$, and $\mathrm{Yb}\left({ }^{5} \mathrm{~F}_{5 / 2} \rightarrow{ }^{2} \mathrm{~F}_{7 / 2}\right)$ transitions in CPL experiments, whereas in $\mathrm{MChD}$ the ${ }^{5} \mathrm{D}_{0} \rightarrow{ }^{7} \mathrm{~F}_{1,2}$ transitions are employed. ${ }^{[6-9]}$

The solids described herein were obtained as byproducts in the hydrothermal synthesis of dense $\mathrm{Na}_{3}\left[\mathrm{LnSi}_{3} \mathrm{O}_{9}\right]$ phosphors. ${ }^{[10-12]}$ Crystals suitable for single-crystal X-ray diffraction were prepared for small-pore materials $\mathrm{Na}_{3}\left[\left(\mathrm{Y}_{0.9} \mathrm{~Tb}_{0.04}{ }^{-}\right.\right.$ $\left.\left.\mathrm{Eu}_{0.025} \mathrm{Ce}_{0.035}\right) \mathrm{Si}_{3} \mathrm{O}_{9}\right] \cdot 3 \mathrm{H}_{2} \mathrm{O}(\mathbf{1} \mathbf{a})$ and $\mathrm{Na}_{3}\left[\left(\mathrm{Y}_{0.995} \mathrm{Er}_{0.005}\right) \mathrm{Si}_{3} \mathrm{O}_{9}\right]$. $3 \mathrm{H}_{2} \mathrm{O}$ (1) $)$. Isostructural $\mathrm{Na}_{3}\left[\left(\mathrm{Y}_{0.7} \mathrm{Eu}_{0.3}\right) \mathrm{Si}_{3} \mathrm{O}_{9}\right] \cdot 3 \mathrm{H}_{2} \mathrm{O}$ (1) c) and $\mathrm{Na}_{3}\left[\left(\mathrm{Y}_{0.70} \mathrm{~Tb}_{0.30}\right) \mathrm{Si}_{3} \mathrm{O}_{9}\right] \cdot 3 \mathrm{H}_{2} \mathrm{O}(\mathbf{1} \mathbf{d})$ were also synthesized as powders and used in the photoluminescence studies. These solids are chiral orthorhombic phases exhibiting a statistical enantiomeric excess (see the Supporting Information). A second type of smaller, monoclinic, centrosymmetric crystals which often cocrystallize with 1, namely, $\mathrm{H}_{0.5} \mathrm{Na}_{2.5}\left[\left(\mathrm{Y}_{0.995} \mathrm{Er}_{0.005}\right) \mathrm{Si}_{3} \mathrm{O}_{9}\right] \cdot 3 \mathrm{H}_{2} \mathrm{O}$ (2), were manually harvested and analyzed on a rotating-anode diffractometer.

The structure of dense $\mathrm{Na}_{3}\left[\mathrm{LnSi}_{3} \mathrm{O}_{9}\right]$ is constructed from complex double spiral chains $\left(\mathrm{Si}_{24} \mathrm{O}_{72}\right)_{\infty}$ with a period of $15.14 \AA$, which connect isolated $\left\{\mathrm{LnO}_{6}\right\}$ octahedra. ${ }^{[10]}$ The chiral (1) and centrosymmetric (2) materials share a common type of $\left(\mathrm{Si}_{3} \mathrm{O}_{9}\right)_{\infty}$ chain (Figure $1 \mathrm{~b}$ and Supporting Information) running along the [100] direction (period of one $a$-axis length, ca. $6.97 \AA)$. Although the $\left(\mathrm{Si}_{24} \mathrm{O}_{72}\right)_{\infty}$ and $\left(\mathrm{Si}_{3} \mathrm{O}_{9}\right)_{\infty}$ chains are different they are both built up of triortho groups $\mathrm{Si}_{3} \mathrm{O}_{10}$, and the latter chain readily transforms into the former on calcining solids $\mathbf{1}$ and 2 at $800{ }^{\circ} \mathrm{C}$. We speculate that the $\mathrm{Si}_{3} \mathrm{O}_{10}$ group is the structural motif that first forms in the gel and templates the synthesis of the three phases. The silicon oxide chains not only connect individual $\left\{\mathrm{LnO}_{6}\right\}$ octahedra but they also isolate them, at minimal Ln $\cdots \operatorname{Ln}$ distances of about 6.32 and $5.88 \AA$ in $\mathbf{1}$ and $\mathbf{2}$, respectively (Figure 1 and Supporting Information1). Such separation of the optically active centers is important because it effectively avoids selfquenching.

Although the $\left(\mathrm{Si}_{3} \mathrm{O}_{9}\right)_{\infty}$ structural motif is similar for both $\mathbf{1}$ and $\mathbf{2}$, the way it is linked to the metal centers is different. Consider the first coordination sphere of the $\left\{(\mathrm{Y}, \mathrm{Ln}) \mathrm{O}_{6}\right\}$ distorted octahedra (see the Supporting Information): whereas in 1 chelation of the metal center by three $\mathrm{Si}_{2} \mathrm{O}_{7}$ moieties ultimately leads to a chiral structure, in $\mathbf{2}$ one of the chelate rings is broken. As a result, the small-pore structure of the former contains one-dimensional mixed 8-ring channels along the [100] direction, which have a cross section of about $2.0 \times 4.0 \AA$ (Figure $1 \mathrm{a}$ ) and host $\mathrm{Na}^{+}$ions and hydrogenbonded water molecules, whereas the comparatively dense framework of the latter has 6-ring tunnels housing $\mathrm{Na}^{+}$and $\mathrm{H}^{+}$ions and water molecules (see the Supporting Information). 


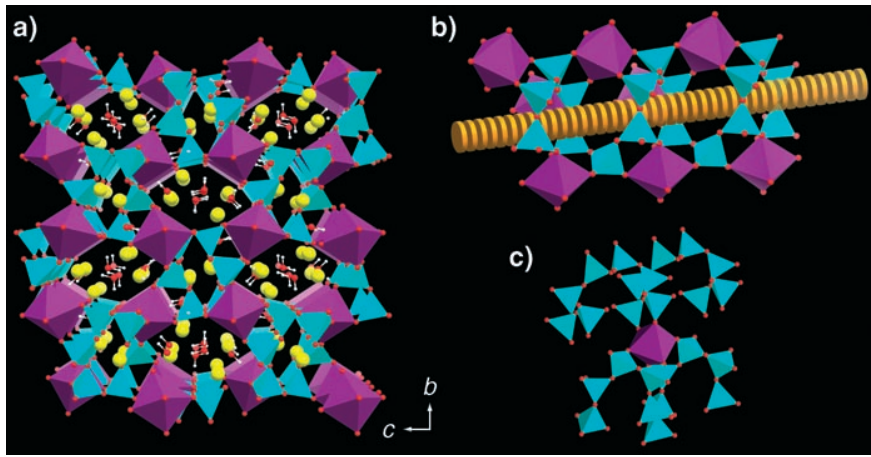

Figure 1. a) Perspective view along the [100] direction of the crystal packing of $\mathbf{1} \mathbf{a}$ and $\mathbf{1} \mathbf{b}$. b) Portion of the anionic frameworks showing one $\left(\mathrm{Si}_{3} \mathrm{O}_{9}\right)_{\infty}$ spiral chain interconnecting individual $\left\{(\mathrm{Y}, \mathrm{Ln}) \mathrm{O}_{6}\right\}$ octahedra $\left(\mathrm{Ln}=\mathrm{Tb}^{3+}, \mathrm{Ce}^{3+}, \mathrm{Eu}^{3+}\right.$, or $\left.\mathrm{Er}^{3+}\right)$. c) Idealized representation of a $\left\{(\mathrm{Y}, \mathrm{Ln}) \mathrm{O}_{6}\right\}$ octahedron connected to two $\left(\mathrm{Si}_{3} \mathrm{O}_{9}\right)_{\infty}$ spirals with opposite handedness. Color code: purple $\left\{(\mathrm{Y}, \mathrm{Ln}) \mathrm{O}_{6}\right\}$; blue $\left\{\mathrm{SiO}_{4}\right\}$; red $\mathrm{O}^{2-}$; yellow $\mathrm{Na}^{+}$; white $\mathrm{H}$.

Excitation and emission spectra of $\mathbf{1 d}$ were recorded at room temperature and $10 \mathrm{~K}$ (Supporting Information). In the excitation spectra, the sharp lines between 280 and $500 \mathrm{~nm}$ are assigned to ${ }^{7} \mathrm{~F}_{6} \rightarrow{ }^{5} \mathrm{D}_{4-0},{ }^{5} \mathrm{~L}_{10},{ }^{5} \mathrm{G}_{6-3},{ }^{5} \mathrm{H}_{7-4}$, and ${ }^{5} \mathrm{~F}_{5,4}$ intraconfigurational forbidden $4 \mathrm{f}^{8} \rightarrow 4 \mathrm{f}^{8}$ transitions of $\mathrm{Tb}^{3+}$. The broad band between 250 and $280 \mathrm{~nm}$ is ascribed to the spinforbidden (high-spin, HS) interconfigurational $4 \mathrm{f}^{8} \rightarrow 4 \mathrm{f}^{7} 5 \mathrm{~d}^{1}$ transition of $\mathrm{Tb}^{3+}$ (see reference [13] and references therein). This type of spin-forbidden fd band may be observed for (heavy) $\mathrm{Ln}^{3+}$ ions with more than seven $4 \mathrm{f}$ electrons at an energy lower than that of spin-allowed (low-spin, LS) fd transitions. The broad band at about $236 \mathrm{~nm}$ is assigned to the spin-allowed (LS) interconfigurational fd transition of $\mathrm{Tb}^{3+}$. The emission spectra of $\mathbf{1 d}$, excited at $265 \mathrm{~nm}$, show a series of sharp lines between 475 and $700 \mathrm{~nm}$, assigned to the ${ }^{5} \mathrm{D}_{4} \rightarrow{ }^{7} \mathrm{~F}_{J}$ $(J=6-1)$ transitions of $\mathrm{Tb}^{3+}$ (see the Supporting Information). The same emission is obtained with excitation at the intra- ${ }^{5} \mathrm{D}_{3}(377 \mathrm{~nm})$ line.

The excitation spectra of $\mathbf{1 c}$ recorded at room temperature and $10 \mathrm{~K}$ (Figure 2) display a series of sharp lines assigned to the ${ }^{7} \mathrm{~F}_{0-2} \rightarrow{ }^{5} \mathrm{D}_{4-0},{ }^{5} \mathrm{~L}_{6},{ }^{5} \mathrm{G}_{2-6},{ }^{5} \mathrm{H}_{3-7}$, and ${ }^{5} \mathrm{~F}_{1-5} \mathrm{Eu}^{3+}$ intra- $4 \mathrm{f}^{6}$ transitions. The faint broad band $\left(4 \mathrm{f}^{6} \rightarrow 4 \mathrm{f}^{5} 5 \mathrm{~d}^{1}\right)$ at high energy is probably the beginning of the spin-allowed, interconfigurational $\mathrm{fd}^{\mathrm{Eu}^{3+}}$ transition band, which normally appears at higher energy than the equivalent $\mathrm{Tb}^{3+}$ band. At $10 \mathrm{~K}$ the spectrum exhibits an additional broad band that peaks at $264.5 \mathrm{~nm}$ and is attributed to ligand-to- $\mathrm{Eu}^{3+}$ charge transfer (CT). The energy $(4.69 \mathrm{eV})$ and full-width at halfmaximum $(0.58 \mathrm{eV})$ of the $\mathrm{CT}$ band are in the range of values reported for many structures containing $\mathrm{Eu}^{3+} \cdot{ }^{[14]}$

The sharp lines of the emission spectra (Figure 3) are assigned to transitions between the first excited nondegenerate ${ }^{5} \mathrm{D}_{0}$ state and the ${ }^{7} \mathrm{~F}_{0-4}$ levels of the fundamental $\mathrm{Eu}^{3+}$ septet. Local-field splitting of the ${ }^{7} \mathrm{~F}_{1,2}$ levels into three and five Stark components (inset in Figure 3, green line) supports the presence of a single low-symmetry $\mathrm{Eu}^{3+}$ environment, as indicated by the crystal structure. Surprisingly, when the sample is excited at the CT band $(265 \mathrm{~nm})$ the number of ${ }^{7} \mathrm{~F}_{1,2}$ Stark components doubles (inset in Figure 3, magenta line).

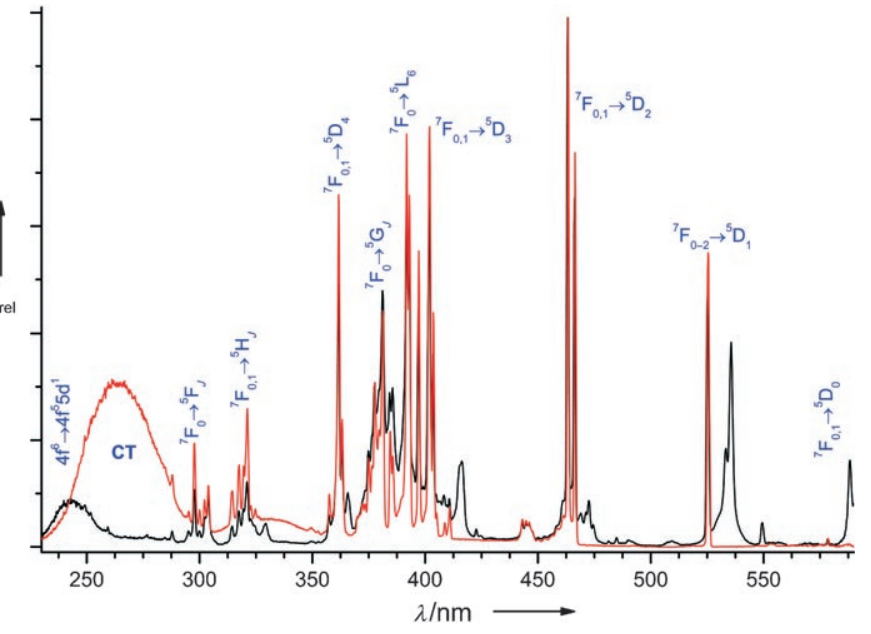

Figure 2. Excitation spectra of $1 \mathrm{c}$ recorded at room temperature (black line) and $10 \mathrm{~K}$ (red line). Emission was monitored at $607.2 \mathrm{~nm}$.

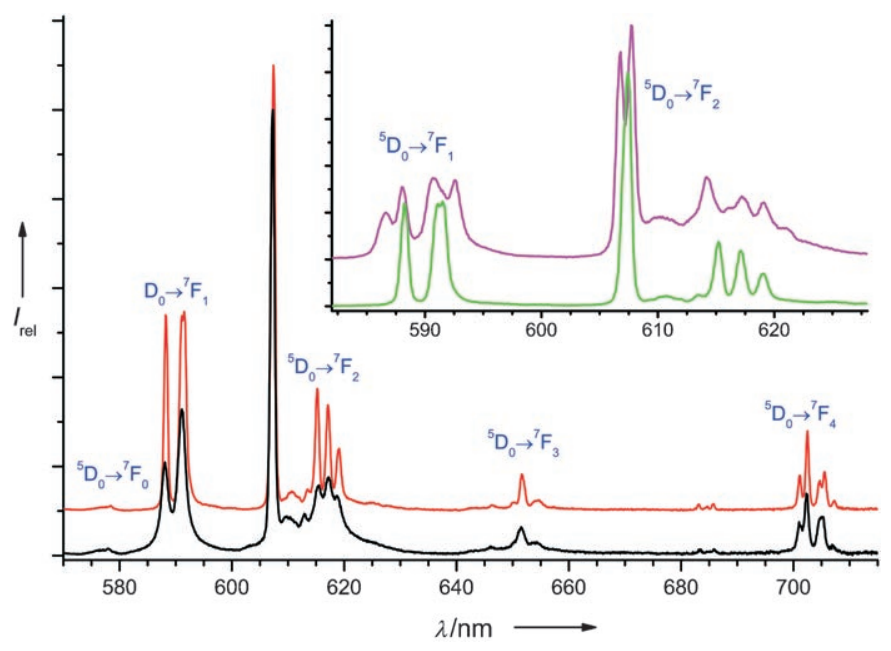

Figure 3. Emission spectra of $\mathbf{1} \mathbf{c}$ recorded at room temperature (black line) and $10 \mathrm{~K}$ (red line). Excitation was performed at $525.4 \mathrm{~nm}$. The inset shows an expansion of the $\mathrm{Eu}^{3+5} \mathrm{D}_{0} \rightarrow{ }^{7} \mathrm{~F}_{1,2}$ transitions, collected at $10 \mathrm{~K}$ and excited at $526 \mathrm{~nm}$ for the ${ }^{5} \mathrm{D}_{1}$ level of $\mathrm{Eu}^{3+}$ (green line) and at $265 \mathrm{~nm}$ for the CT band (magenta line).

We note that this is only observed between 10 and about $120 \mathrm{~K}$, the temperature range in which the CT band is also detected (despite the fact that the X-ray data, collected at $100 \mathrm{~K}$, call for the presence of a single $\mathrm{Eu}^{3+}$ site).

Because the ${ }^{5} \mathrm{D}_{0} \rightarrow{ }^{7} \mathrm{~F}_{0}$ line is very faint, we did not draw any conclusions from its evolution when the excitation wavelength was varied from the $\mathrm{CT}$ to the intra- $4 \mathrm{f}$ lines. The relative intensities of the two main ${ }^{5} \mathrm{D}_{0} \rightarrow{ }^{7} \mathrm{~F}_{2}$ Stark components depend on the particular sample studied (see the Supporting Information). This observation constitutes first (though not unequivocal) evidence for the presence of two enantiomers in 1c. Moreover, the enantioselective detection of $\mathrm{Eu}^{3+}$-containing molecular compounds by $\mathrm{CPL}$ and $\mathrm{MChD}$ has been found to be much more sensitive in the magnetic dipole-allowed ${ }^{5} \mathrm{D}_{0} \rightarrow{ }^{7} \mathrm{~F}_{1}$ transition than in the induced electric-dipole ${ }^{5} \mathrm{D}_{0} \rightarrow{ }^{7} \mathrm{~F}_{2}$ transition. ${ }^{[6,8,9]}$ In 1c we observe maximum splittings of the ${ }^{5} \mathrm{D}_{0} \rightarrow{ }^{7} \mathrm{~F}_{1}$ transition of 172 and 
$95 \mathrm{~cm}^{-1}$, respectively for excitation at the CT band and intra$4 \mathrm{f}^{6}$ lines (inset in Figure 3). For the ${ }^{5} \mathrm{D}_{0} \rightarrow{ }^{7} \mathrm{~F}_{2}$ transition the maximum splittings are 373 and $310 \mathrm{~cm}^{-1}$, respectively, for the same excitations. Thus, the maximum splitting difference is significantly larger for the ${ }^{5} \mathrm{D}_{0} \rightarrow{ }^{7} \mathrm{~F}_{1}$ transition $\left(77 \mathrm{~cm}^{-1}\right.$, compared with $63 \mathrm{~cm}^{-1}$ for the other transitions).

Measurements of ${ }^{5} \mathrm{D}_{0}$ lifetimes for $\mathrm{Na}_{3}$ $\left[\left(\mathrm{Y}_{1-a} \mathrm{Eu}_{a}\right) \mathrm{Si}_{3} \mathrm{O}_{9}\right] \cdot 3 \mathrm{H}_{2} \mathrm{O} \quad(a=0.2, \quad 0.3$; see the Supporting Information) clearly support this conclusion. In all measurements, the ${ }^{5} \mathrm{D}_{0}$ decay curves are well fitted by a single exponential (Supporting Information). At $10 \mathrm{~K}$ the two samples display a similar lifetime $((1.59 \pm 0.01) \mathrm{ms})$ for excitation in the ${ }^{5} \mathrm{D}_{1}$ level $(526 \mathrm{~nm})$ and detection in the strongest ${ }^{7} \mathrm{~F}_{2}$ Stark component $(608.5 \mathrm{~nm})$. However, excitation in the CT band leads to different lifetimes. Whereas the sample with $a=0.2$ has the same lifetime for the two main ${ }^{7} \mathrm{~F}_{2}$ Stark components at 607.8 and $609.1 \mathrm{~nm}((1.48 \pm 0.01) \mathrm{ms})$, that with $a=0.3$ displays different lifetimes of $(1.39 \pm 0.01)$ and $(1.54 \pm 0.01) \mathrm{ms}$ for detection at these wavelengths, respectively.

We now try to rationalize the unusual detection of enantiomeric domains by photoluminescence spectroscopy with excitation by unpolarized light and in the absence of an external applied magnetic field. Consider Figure 1c: Structurally, the $\mathrm{Y}^{3+} / \mathrm{Eu}^{3+}$ ions link in different ways to two adjacent $\left(\mathrm{Si}_{3} \mathrm{O}_{9}\right)_{\infty}$ spiral chains which, for the sake of argument, we assume to be enantiomeric. Each $\mathrm{Y}^{3+} / \mathrm{Eu}^{3+}$ octahedron shares four corners with a spiral of a given handedness, and two corners with a spiral of opposite handedness.

When the material is excited on the CT band, expansion of the $\mathrm{Eu}^{3+}-\mathrm{O}$ bonds of the two adjacent enantiomeric spirals gives rise to two discernible $\mathrm{Eu}^{3+}$ local environments. Indeed, a CT transition involves considerable reorganization of the charge density distribution around the $\mathrm{Eu}^{3+}$ ion, which is accompanied by expansion of the $\mathrm{Eu}^{3+}-\mathrm{O}$ bonds in the excited state. ${ }^{[15]}$ The above-mentioned decrease in the ${ }^{5} \mathrm{D}_{0}$ lifetime for CT excitation (Supporting Information) lends support to this $\mathrm{Eu}^{3+}-\mathrm{O}$ expansion. Moreover, as the two main ${ }^{5} \mathrm{D}_{0} \rightarrow{ }^{7} \mathrm{~F}_{2}$ transitions of the sample with $a=0.2$ exhibit similar intensities and lifetimes, this material does not contain a significant enantiomeric excess. In contrast, the emission spectrum of the sample with $a=0.3$ suggests a small enantiomeric excess, slight difference in intensity of the two lines, and distinct lifetimes (see the Supporting Information). Further work is in progress to fully understand the intriguing phenomenon of domain enantioselectivity in microporous framework silicates by photoluminescence spectroscopy.

In conclusion, to the best of our knowledge, discrimination between enantiomeric domains has so far only been achieved by using $\mathrm{CPL}$ or $\mathrm{MChD} .^{[6-9]}$ Our results raise the exciting possibility that $\mathrm{Eu}^{3+}$ photoluminescence spectroscopy may, at least in certain cases, be used to detect, and possibly quantify, enantiomeric domains in chiral frameworks.

\section{Experimental Section}

The syntheses of rare-earth-metal silicates were carried out in teflonlined autoclaves under static hydrothermal conditions in ovens preheated to $150-230^{\circ} \mathrm{C}$. All lanthanide salts were of $99.9 \%$ purity.
In all the syntheses, autoclaves were removed and quenched in cold water after an appropriate time. The obtained microcrystalline powders were filtered, washed at room temperature with distilled water, and dried at $100^{\circ} \mathrm{C}$.

Typical synthesis of single crystals of $\mathbf{1 a}$ : An alkaline solution was made by mixing sodium silicate solution $\left(6.83 \mathrm{~g}, 27 \mathrm{wt} \% \mathrm{SiO}_{2}, 8 \mathrm{wt} \%\right.$ $\mathrm{Na}_{2} \mathrm{O}$, Merck), $\mathrm{H}_{2} \mathrm{O}$ (10.07 g), and $\mathrm{NaOH}$ (6.59 g, Panreak). A mixture of $\mathrm{YCl}_{3} \cdot 6 \mathrm{H}_{2} \mathrm{O}$ (1.05 g, Aldrich), $\mathrm{TbCl}_{3} \cdot 6 \mathrm{H}_{2} \mathrm{O}(0.058 \mathrm{~g}$, Aldrich), $\mathrm{EuCl}_{3} \cdot 6 \mathrm{H}_{2} \mathrm{O}\left(0.035 \mathrm{~g}\right.$, Aldrich), and $\mathrm{CeCl}_{3} \cdot 7 \mathrm{H}_{2} \mathrm{O}(0.050 \mathrm{~g}$, Aldrich) in $\mathrm{H}_{2} \mathrm{O}(10.0 \mathrm{~g})$ was added to this solution, and the solution was stirred thoroughly. The gel, with composition $2.97 \mathrm{Na}_{2} \mathrm{O}: 1.00 \mathrm{SiO}_{2}: 0.057 \mathrm{Y}_{2} \mathrm{O}_{3}: 0.0021 \mathrm{~Tb}_{2} \mathrm{O}_{3}: 0.0014 \mathrm{Eu}_{2} \mathrm{O}_{3}: 0.0014$

$\mathrm{Ce}_{2} \mathrm{O}_{3}: 36.3 \mathrm{H}_{2} \mathrm{O}$, was heated in autoclaves (volume $37 \mathrm{~cm}^{3}$ ) for $8 \mathrm{~d}$ at $230^{\circ} \mathrm{C}$. The resulting sample also contained single crystals of 2 and dense $\mathrm{Na}_{3}\left[\left(\mathrm{Y}_{0.9} \mathrm{~Tb}_{0.04} \mathrm{Eu}_{0.025} \mathrm{Ce}_{0.035}\right) \mathrm{Si}_{3} \mathrm{O}_{9}\right]$ (Supporting Information). ${ }^{[10-12]}$

Typical synthesis of single crystals of 2: An alkaline solution was made by mixing sodium silicate solution $\left(7.91 \mathrm{~g}, 27 \mathrm{wt} \% \mathrm{SiO}_{2}, 8 \mathrm{wt} \%\right.$ $\mathrm{Na}_{2} \mathrm{O}$, Merck), $\mathrm{H}_{2} \mathrm{O}$ (12.20 g), and $\mathrm{NaOH}$ (7.72 g, Panreak). A mixture of $\mathrm{YCl}_{3} \cdot 6 \mathrm{H}_{2} \mathrm{O}\left(1.293 \mathrm{~g}\right.$, Aldrich) and $\mathrm{ErCl}_{3} \cdot 6 \mathrm{H}_{2} \mathrm{O}(0.008 \mathrm{~g}$, Aldrich) in $\mathrm{H}_{2} \mathrm{O}(10.0 \mathrm{~g})$ was added to this solution and the solution was stirred thoroughly. The gel, with composition $3.00 \mathrm{Na}_{2} \mathrm{O}: 1.00 \mathrm{SiO}_{2}: 0.060 \mathrm{Y}_{2} \mathrm{O}_{3}: 0.0003 \mathrm{Er}_{2} \mathrm{O}_{3}: 34.7 \mathrm{H}_{2} \mathrm{O}$, was heated in autoclaves (volume $42 \mathrm{~cm}^{3}$ ) for $5 \mathrm{~d}$ at $230{ }^{\circ} \mathrm{C}$. The resulting sample also contains small amounts of $\mathbf{1 b}$ and dense $\mathrm{Na}_{3}\left[\left(\mathrm{Y}_{0.995} \mathrm{Er}_{0.005}\right) \mathrm{Si}_{3} \mathrm{O}_{9}\right] .{ }^{[10-12]}$ Ultrasonication of a water suspension of the material disperses the crystals of 2. Unlike the dense material $^{[10-12]}$ and $\mathbf{1 b}$ crystals, crystals of $\mathbf{2}$ remain in the aqueous phase and are easily isolated.

Pure samples of $\mathbf{1 c}$ and $\mathbf{1 d}$ were prepared from a similar initial gel by introducing the desired $\mathrm{Y}^{3+}$ and $\mathrm{Eu}^{3+}$ or $\mathrm{Tb}^{3+}$ contents and heating for $13 \mathrm{~d}$ at $150^{\circ} \mathrm{C}$ (see the Supporting Information).

The chemical composition of the samples was ascertained by energy-dispersive $\mathrm{X}$-ray spectroscopy. Thermogravimetry confirmed that materials $\mathbf{1}$ and $\mathbf{2}$ contain three water molecules per formula unit.

Further details on the crystal structure investigations may be obtained from the Fachinformationszentrum Karlsruhe, 76344 Eggenstein-Leopoldshafen, Germany (fax: (+49)7247-808-666; e-mail: crysdata@fiz-karlsruhe.de), on quoting the depository numbers CSD-415853 (1a), -415852 (1b), and -415852 (2). See also the Supporting Information.

Crystal data for 1a: $\mathrm{H}_{24} \mathrm{Ce}_{0.14} \mathrm{Eu}_{0.10} \mathrm{Na}_{12} \mathrm{O}_{48} \mathrm{Si}_{12} \mathrm{~Tb}_{0.16} \mathrm{Y}_{3.60}, \quad M=$ 1785.47, orthorhombic, space group $P 2_{1} 2_{1} 2_{1}, Z=1, a=6.9724(14)$, $b=11.687(2), \quad c=13.404(3) \AA, \quad V=1092.2(4) \AA^{3}, \quad \mu\left(\mathrm{Mo}_{\mathrm{K} \alpha}\right)=$ $5.864 \mathrm{~mm}^{-1}, \rho_{\text {calcd }}=2.715 \mathrm{~g} \mathrm{~cm}^{-3}$. Of a total of 10557 reflections collected, 2408 were independent $\left(R_{\text {int }}=0.0525\right)$. Crystal size $0.08 \times$ $0.07 \times 0.04 \mathrm{~mm}$. Final $R 1=0.0288[I>2 \sigma(I)]$ and $w R 2=0.0650$ (all data).

Crystal data for $\mathbf{1 b}: \mathrm{H}_{24} \mathrm{Er}_{0.02} \mathrm{Na}_{12} \mathrm{O}_{48} \mathrm{Si}_{12} \mathrm{Y}_{3.98}, M=1762.36$, orthorhombic, space group $P 22_{1} 2_{1}, Z=1, a=6.9610(14), b=11.669(2), c=$ 13.375(3) $\AA, \quad V=1086.4(4) \AA^{3}, \quad \mu\left(\mathrm{Mo}_{\mathrm{K} a}\right)=5.892 \mathrm{~mm}^{-1}, \quad \rho_{\text {calcd }}=$ $2.694 \mathrm{~g} \mathrm{~cm}^{-3}$. Of a total of 9102 reflections collected, 2226 were independent $\left(R_{\text {int }}=0.0453\right)$. Crystal size $0.10 \times 0.09 \times 0.06 \mathrm{~mm}$. Final $R 1=0.0268[I>2 \sigma(I)]$ and $w R 2=0.0566$ (all data).

Crystal data for $2: \mathrm{H}_{26} \mathrm{Er}_{0.02} \mathrm{Na}_{10} \mathrm{O}_{48} \mathrm{Si}_{12} \mathrm{Y}_{3.98}, M=1718.40$, monoclinic, space group $P 2_{1} / n, Z=1, a=9.073(4), b=8.823(4), c=$ 12.963(5) $\AA, \quad \beta=107.68(2)^{\circ}, \quad V=988.8(7) \AA^{3}, \quad \mu\left(\mathrm{Mo}_{\mathrm{K} \alpha}\right)=$ $13.675 \mathrm{~mm}^{-1}, \rho_{\text {cald }}=2.886 \mathrm{~g} \mathrm{~cm}^{-3}$. Of a total of 2571 reflections collected, 990 were independent $\left(R_{\text {int }}=0.1025\right)$. Crystal size $0.05 \times$ $0.05 \times 0.01 \mathrm{~mm}^{3}$. Final $R 1=0.0882[I>2 \sigma(I)]$ and $w R 2=0.2095$ (all data).

Photoluminescence measurements were performed on a Fluorolog-3 Model FL3-2T with double excitation spectrometer (Triax 320 ), fitted with a 1200 -grooves $\mathrm{mm}^{-1}$ grating blazed at $330 \mathrm{~nm}$, and a single emission spectrometer (Triax 320), fitted with a 1200 -grooves $\mathrm{mm}^{-1}$ grating blazed at $500 \mathrm{~nm}$, coupled to an R928P photomultiplier. The excitation source was a $450-\mathrm{W}$ xenon lamp. Excitation 
spectra were corrected from 240 to $600 \mathrm{~nm}$ for the spectral distribution of the lamp intensity by using a photodiode reference detector. Emission and excitation spectra, recorded between $10 \mathrm{~K}$ and room temperature in $20-30-K$ steps by using a closed-cycle $\mathrm{He}$ cryostat, were also corrected for the spectral response of the monochromators and the detector by using typical correction spectra provided by the manufacturer. Time-resolved measurements were carried out with a 1934D3 phosphorimeter coupled to the Fluorolog-3 and a Xe-Hg flash lamp (6 $\mu$ s/pulse half width and tail of 20-30 $\mu$ s) was used as excitation source.

Received: July 17, 2006

Revised: September 11, 2006

Published online: October 19, 2006

Keywords: hydrothermal synthesis - lanthanides .

luminescence $\cdot$ microporous materials $\cdot$ silicates

[1] J. Rocha, M. W. Anderson, Eur. J. Inorg. Chem. 2000, 801-818.

[2] J. Rocha, Z. Lin, Reviews in Mineralogy and Geochemistry, Vol. 57 (Eds.: G. Ferraris, S. Merlino), Mineralogical Society of America, Geochemical Society, 2005, chap. 6, pp. 173-201.

[3] M. Tsapatsis, AIChE J. 2002, 48, 654-660.

[4] J. M. Newsham, M. M. J. Treacy, W. T. Koetsier, C. B. De Gruyter, Proc. R. Soc. London Ser. A 1988, 420, 375-405.

[5] M. W. Anderson, O. Terasaki, T. Ohsuna, A. Philippou, S. P. Mackay, A. Ferreira, J. Rocha, S. Lidin, Nature 1994, 367, 347 351.

[6] G. L. J. A. Rikken, E. Raupach, Nature 1997, 390, 493-494.

[7] F. S. Richardson, J. P. Riehl, Chem. Rev. 1977, 77, 773-792.

[8] J. P. Riehl, F. S. Richardson, Chem. Rev. 1986, 86, 1-16.

[9] J.-C. G. Bünzli, C. Piguet, Chem. Soc. Rev. 2005, 34, 1048-1077.

[10] D. Ananias, J. P. Rainho, A. Ferreira, M. Lopes, C. M. Morais, J. Rocha, L. D. Carlos, Chem. Mater. 2002, 14, 1767-1772.

[11] D. Ananias, A. Ferreira, L. D. Carlos, J. Rocha, Adv. Mater. 2003, 15, 980-985.

[12] D. Ananias, L. D. Carlos, J. Rocha, Opt. Mater. 2006, 28, 582 586.

[13] D. Ananias, M. Kostova, F. A. A. Paz, A. Ferreira, L. D. Carlos, J. Klinowski, J. Rocha, J. Am. Chem. Soc. 2004, 126, 10410 10417.

[14] P. Dorenbos, J. Phys. Condens. Matter 2003, 15, 8417-8434.

[15] L. van Pieterson, M. Heeroma, E. de Heer, A. Meijerink, $J$. Lumin. 2000, 31, 177-193. 